\title{
A MATEMÁTICA DE RENÉ DESCARTES
}

\section{RENÉ DESCARTES' MATHEMATICS}

\author{
Róbson Lousa dos Santos ${ }^{1}$ \\ Universidade Federal de Goiás \\ Fernanda Gomes da Cruz ${ }^{2}$ \\ Universidade Federal de Goiás
}

\begin{abstract}
Resumo
O filósofo e matemático francês René Descartes nasceu em plena Revolução Científica e exerceu forte influência sobre o rumo que a ciência tomaria posteriormente. Conhecido como pai da Filosofia Moderna por suas inúmeras contribuições para a filosofia, deu importantes contribuições para a matemática, relacionando a Geometria e a Aritmética e a Álgebra, dando bases para a Geometria Analítica cuja criação muitas vezes lhe é atribuída, além de outras contribuições como o tão largamente usado plano cartesiano. Para a Álgebra e a Aritmética, sua contribuição vai além do uso destas como ferramentas para a Geometria, o matemático contribuiu com a notação que ainda na atualidade é utilizada.
\end{abstract}

Palavras-chaves: Matemática cartesiana. René Descartes. Revolução Científica. História da Matemática.

\begin{abstract}
The French philosopher and mathematician René Descartes was born in the Scientific Revolution and exerted a strong influence on the direction that science would later. Known as the father of Modern Philosophy for its many contributions to philosophy, he has made important contributions to mathematics. He connected Geometry and Arithmetic and Algebra, giving foundations for Analytic Geometry whose creation is often attributed to him, as well as other contributions as the so widely used Cartesian Plane. For Algebra and Arithmetic, your contribution goes beyond the use of these as tools for Geometry, the mathematician contributed for the notation that still today is used.
\end{abstract}

Keywords: Cartesian Mathematics. René Descartes. Scientific Revolution. History of Mathematics.

\section{Introdução}

O filósofo e matemático francês René Descartes em seus estudos e escritos deixou inúmeras contribuições, tais como, o plano cartesiano como conhecemos hoje, o pensamento

\footnotetext{
${ }^{1}$ robsonlousa@hotmail.com.

2 fernandacruz10@hotmail.com.
} 
cartesiano e suas influências, não só na ciência matemática, mas para a ciência em geral na chamada Revolução Científica.

Descartes acreditava que se é possível reduzir (ou expandir) o mundo em termos matemáticos, buscando provar tal afirmação, ele deu contribuições à matemática e à física a partir deste pensamento, o que fica evidente em sua obra $O$ mundo ou tratado da luz, na qual ele trata elementos físicos como elementos matemáticos.

O pensamento cartesiano foi aplicado à matemática, pelo próprio pensador, em sua obra A geometria publicada em 1637 como apêndice à sua principal obra Discurso do método. Nesta obra, o matemático relaciona geometria com aritmética e álgebra, utilizando métodos como o do matemático François Viète (1540-1603) de utilizar letras para representar números e aplicando mais de fato o seu próprio método. Em suas próprias palavras, em uma carta direcionada a Mersenne, Descartes destaca,

\footnotetext{
Não desejo falar em prol de mim mesmo, mas uma vez que poucas pessoas conseguem entender a minha geometria e uma vez que o senhor deseja que forneça minha opinião sobre isso, eu julgo que vale dizer que isto é tudo que eu pude esperar, e isso na Dióptrica e nos Meteoros eu apenas tentei persuadir as pessoas que o meu método é melhor que o ordinário. Eu provei isto na Geometria, pois no início eu resolvi uma questão [Problema de Pappus] que, segundo Pappus, não poderia ser resolvida por nenhum dos antigos geômetras (DESCARTES, 2009, p. 230).
}

O filósofo também contribui com a matemática dando uma solução para o problema da quadratura do círculo e também solucionando o Problema de Pappus, sendo que a partir desta solução, ele propôs a criação do sistema de coordenadas cartesianas, que se encontra em sua obra A geometria.

É válido e necessário ressaltar a ênfase que este trabalho dará para esta última obra especificamente, pois nela se encontram diversas contribuições matemáticas do autor. Nela se tem indícios tanto da criação da geometria analítica, quanto do plano cartesiano. Também é nela que se encontra sugestões para a notação que passou a ser usada na álgebra e é usual ainda nos dias de hoje.

\section{Vida e Obra}

René Descartes, nascido em La Haye - atualmente chamada La Haye Descartes -, França, em 31 de março de 1596, e falecido em Estocolmo, Suécia, em 11 de fevereiro de $1650^{3}$,

\footnotetext{
${ }^{3}$ Em REALE \& ANTISERI (2004) encontra-se a data de 2 de fevereiro de 1650 referente ao falecimento de Descartes, porém as demais fontes que citam a data do evento, traz a data de 11 de fevereiro de 1650.
}

Boletim Cearense de Educação e História da Matemática - Volume 03, Número 08, 30 - 46(2016) 
foi filósofo, físico e matemático, atualmente é conhecido como o pai da Filosofia Moderna. Estudou na renomada Escola Jesuíta La Flèche e na Universidade de Pointers, onde cursou Medicina e Direito. Ao longo de seus estudos, foi se interessando cada vez mais pelo estudo dos elementos matemáticos. Descartes desenvolveu grande fascínio pela ciência, acreditando que "a matemática era a única chave necessária para desvendar os segredos da natureza" (SOUZA, 2003, p. 87), quando passou a abandonar, gradualmente, as outras áreas pelas quais se interessava.

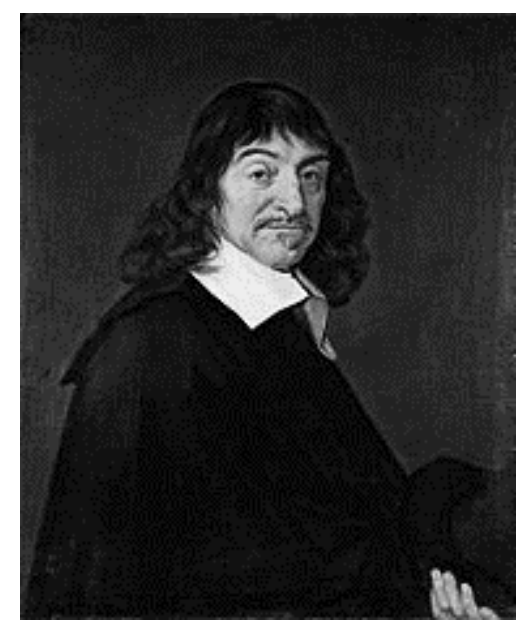

Figura 1. René Descartes

Durante os seus estudos na Escola Jesuíta La Flèche e na Universidade de Pointres, Descartes se viu inquieto em relação à direção que a filosofia e matemática estavam tomando. Por tal motivo, durante toda a sua produção, não dispensou críticas ao aristotelismo e a matemática e lógica tradicionais, pois ele "percebia a falta de um método que ordenasse o pensamento e, ao mesmo tempo, fosse instrumento heurístico e de fundamentação verdadeiramente eficaz" (REALE \& ANTISERI, 2004, p. 287). Paradoxalmente, somente com o surgimento desta inquietação, tem bases para criar um método que seria capaz de influenciar até mesmo as ciências que surgiriam anos após a sua morte.

Sua principal obra, O Discurso do Método, publicada pela primeira vez em 1637, trazia como apêndice três outras importantes obras Os Meteoros, na qual Descartes afirma não existir vazio, A Dióptrica, que trata principalmente sobre a construção de vidros, e A Geometria, que cuidou de elementos geométricos. Esta é dividida em três partes ${ }^{4}$, sendo que o "[...] livro

\footnotetext{
${ }^{4} \mathrm{Na}$ obra original, cada uma das três partes da obra A geometria era chamada de "Livro".
} Boletim Cearense de Educação e História da Matemática - Volume 03, Número 08, 30 - 46(2016) 
primeiro [trata]: [d]os problemas que se podem construir sem empregar mais do que círculos e linhas retas [seguimentos de retas]. Livro segundo: [d]a natureza das linhas curvas. Livro terceiro: [d]a construção dos problemas sólidos ou mais que sólidos” (VAZ, 2005).

Além desta obra, outros títulos completam sua obra. Regras para a direção do espírito, obra inacabada que não há um consenso entre os estudiosos sobre a data em que foi escrita, que varia entre 1620 a 1635; O mundo ou o tratado da luz, redigido entre 1632 e 1633, somente foi publicado anos depois de sua morte, pois defendia ideias contrárias às da igreja na época, motivo pelo qual o físico italiano Galileu Galilei (1564-1642) havia sido condenado por defender o sistema heliocêntrico de Copérnico (1473-1543); Meditações Metafísicas de 1641, na qual são expostas seis meditações sobre a metafísica; Princípios da Filosofia de 1644, onde fala dos princípios do conhecimento humano; e As paixões da Alma de 1649 que fala sobre as paixões e virtudes do homem, trazendo definições de inúmeras destas.

Descartes morre em 1650 em Estocolmo vítima de uma pneumonia devido às altas temperaturas. No ano anterior havia recebido o convite da rainha Cristina da Suécia para se dirigir a tal local. Ele não recusou o convite, principalmente por estar decepcionado ao saber que os professores da Universidade de Leida, na Holanda, proibiram o estudo de suas obras (REALE, 2014).

\section{O Sonho de Descartes}

Segundo inúmeras fontes, na noite de 10 de novembro de 1619 Descartes teve um sonho no qual "o anjo da verdade" lhe aparecia e lhe inspirou a ver a possibilidade de relacionar tudo com a matemática (NIEBEL, HORN, SCHNÄDELBACH, 2000; ROSSI, 2001; SOUZA, 2003). Após este fato, o filósofo estuda como concretizar esta inspiração e relacionar tudo com a matemática.

Tendo este objetivo em vista, percebe-se que "destitui-se, com Descartes, as qualidades do objeto para que ele seja considerado uma quantidade discreta e descontínua [...]. A concretude da matéria - a sua substancialidade - está, portanto, na sua abertura à quantificação" (ANDRADE, 2008, p. 16). Não por acaso, ele começa a criar uma geometria aritmetizada, trabalhando a geometria (de objetos contínuos) com ferramentas da aritmética que possui objetos discretos.

Reafirmando seu objetivo, em Regras para a direção do espírito, ele deixa claro que lhe pareceu ser 
óbvio relacionar com a Matemática tudo aquilo em que apenas se examina a ordem e medida, sem ter em conta se é em números, figuras, astros, sons, ou em qualquer outro objeto que semelhante medida se deve procurar; e, por conseguinte, deve haver uma ciência geral que explique tudo o que se pode investigar acerca da ordem e da medida, sem as aplicar a uma matéria especial: esta ciência designa-se, não pelo vocábulo suposto, mas pelo vocábulo já antigo e aceite pelo uso de Matemática universal, porque esta contém tudo o que contribui para que as outras ciências se chamem partes da Matemática. [O] quanto a Matemática universal sobrepuja em utilidade e facilidade as outras ciências que lhe estão subordinadas, vê-se perfeitamente no fato de abarcar os mesmos objetos que estas últimas e, além disso, muitos outros; no fato ainda de que as suas dificuldades, se é que contém algumas, existem também nestas últimas ciências, com outras ainda provenientes dos seus objetos particulares e que ela não tem (DESCARTES, 1989, p. 10).

Embora sua obra $O$ mundo ou tratado da luz seja uma obra mais física que matemática, por tratar de movimento, velocidade, massa e outro elementos físicos, percebe-se a tentativa de reduzir (ou expandir) o mundo (físico) em elementos matemáticos, pois, segundo Souza (2003, p. 87), "as matemáticas pareciam ser as únicas a trazer alguma certeza ao pensamento de Descartes e, ao mesmo tempo, a lhe proporcionar grandes esperanças em seu projeto". Esta redução (ou expansão) era principalmente em elementos geométricos, pois eram considerados os mais legítimos desde a publicação de Os elementos de Euclides (ROQUE, 2012), principalmente a geometria que Descartes (2009, p. 239-140) chamou de elementar, ou seja, os elementos que podem ser construídos usando-se apenas régua e compasso, mesmo sendo “óbvio para toda a ciência matemática que ambos os campos [geometria, aritmética e álgebra] se relacionavam" (SOUZA, 2003, p. 88).

Andrade (2008, p. 16-17) percebe esta tentativa na física cartesiana:

Em decorrência do caráter inerte que a matéria recebe na física cartesiana, a noção de causalidade, compreendida por Aristóteles como a expressão das quantidades sensíveis do corpo, inscrita na essência do mesmo e, por conseguinte, responsáveis pelo seu movimento em direção à ordem natural, é trasposta para a esfera do fortuito. Ou seja, retira-se da física os componentes que poderiam fornecer subsídios para interpretações fortemente qualitativa[s] do movimento - que se concentram em cada um dos aspectos particulares da composição do corpo -, tornando-a mais modesta e menos pretensiosa.

Vale ainda ressaltar que

a comparação é na ciência cartesiana o modo de conduzir os sentidos a perceberem, sobretudo por meio de figuras, o sistema mecânico que engrena a repetição invariável do mundo [...]. Tornam mais fácil a compreensão de fenômenos que ocorrem no interior dos corpos e que não podem ser percebidas diretamente por nossos sentidos. (ANDRADE, 2008, p. 13). 
Descartes também tinha certa preocupação com a popularização das ciências, principalmente de suas obras, porém, ele não era o único filósofo com esta preocupação. $\mathrm{Na}$ Itália, por exemplo, seu contemporâneo Galileu Galilei também publicou uma obra em italiano, sua língua natal. Um fato importante da divulgação da ciência fica evidente no final de sua obra Discurso do Método, onde ele esclarece alguns motivos por não ter escrito a obra em latim, como era comum antes e depois dele no meio científico, e ter escrito a primeira obra filosófica em francês (Descartes, 1985, p. 92, nota 261),

E, se escrevo em francês, que é a língua do meu país, e não em latim, que é a de meus preceptores, é porque espero que aqueles que usam apenas sua razão natural inteiramente pura julgarão melhor minhas opiniões do que aqueles que só acreditam nos livros antigos. (DESCARTES, 1985, p. 92).

Reafirmando sua vontade de se fazer entendido, no início da carta de Descartes ao tradutor que Princípios da Filosofia (que foi escrito primeiramente em latim), ele afirma estar contente com a "límpida e exata versão" dos Princípios, tanto que lhe dava "a esperança de que [eles] sejam agora lidos em francês por maior número de pessoas, do que o foram em latim" e, o mais importante para o autor, é que eles fossem "melhor compreendidos" (DESCARTES, 1968, p. 27).

Quanto ao pensamento cartesiano, vale ainda ressaltar que

para Descartes, as demonstrações matemáticas não tinham somente o papel de convencer e estabelecer uma certeza; deviam sobretudo esclarecer a natureza do problema e propor métodos de invenção direta que permitissem resolvê-los. Por isso ele rejeitava a demonstração por absurdo (ROQUE, 2012, p. 318).

Para se fazer demonstração por absurdo, é necessário conhecer previamente o resultado a ser provado, necessitando-se de outros métodos para prová-lo, ou a suposição de que o resultado esperado seja verdadeiro, porém, para Descartes, o que importa é o método para descobrir novos resultados matemáticos e, por conseguinte, novos conhecimentos, fazendo com que a filosofia se tornasse mais epistemológica.

Porém, Descartes não criticava apenas a demonstração por absurdo da herança deixada pela lógica tradicional/aristotélica, mas também criticou a Escolástica e o Aristotelismo como um todo. Segundo Reale \& Antiseri (2004, p. 287), “até no melhor do seu desempenho, a lógica tradicional nada mais faz do que ajudar a expor a verdade, mas não a conquistá-la".

Neste sentido, 
[o] método matemático [de Descartes], com o qual pretende dar conta dos fenômenos naturais, consiste em distinguir duas etapas: intuição e a dedução. [...] Descartes concebe a intuição como sendo a concepção que a mente lúcida e atenta fornece, tão pronta e distintamente que ficamos totalmente livres de dúvida a respeito daquilo que compreendemos. [...] Por dedução, ele entende a cadeia de inferências necessárias, a partir dos fatos conhecidos intuitivamente, sendo que a certeza de sua conclusão é conhecida pelas intuições e pela memória de sua conexão necessária no pensamento (SOUZA, 2003, p. 89).

De mesmo modo, Descartes

falava da intuição evidente (evidens intuitus), como um dos dois caminhos que levam ao conhecimento certo (o outro é o da "dedução necessária”), entendendo com ela a apreensão de qualquer objeto mental: "A intuição da mente estende-se às coisas, ao conhecimento de suas interconexões necessárias e a tudo o que o intelecto experimenta com precisão em si mesmo ou na imaginação" (Regulae ad directionem ingenii, p. 12, apud ABBAGNANO, 2007, p. 592).

Descartes nasceu em plena Revolução Científica, onde o uso de instrumentos não mais é visto como algo a deslegitimar a ciência (STRUIK, 1989). Um exemplo é o uso do telescópio por Galileu nas descobertas de outros corpos celestes. O próprio Descartes, em sua A Dióptrica, trata tanto da refração da luz quanto de construções de instrumentos a partir do vidro, onde ele atesta ser seu método mais eficiente que o utilizado pelos construtores de vidro de sua época, pois era um método científico.

\section{A Quadratura do Círculo}

Os antigos geômetras gregos deixaram alguns problemas em aberto para a matemática, problemas demoraram séculos para serem provados, sendo que alguns destes não possuem solução fazendo uso apenas da régua e compasso (que era a propostas dos antigos). Um deste problemas ficou conhecido como a quadratura do círculo, que consiste em encontrar um quadrado que possua a mesma área que a de um círculo utilizando métodos geométricos, isto é, fazendo uso apenas da régua e compasso. Tal problema foi estudado por Descartes e portanto, merece ser citado.

Sabe-se que ele acreditava ser impossível solucionar o problema da quadratura do círculo. Em suas próprias palavras,

Mas, quanto às questões de geometria que eles vos prometem me propor, as quais não
conseguem solucionar e creem não poder serem resolvidas pelo meu método, eu penso
que me encontro em uma posição desvantajosa. Com efeito, primeiramente, é contra
o estilo dos geômetras propor aos outros questões que eles mesmos não podem
resolver. Depois, há as que são impossíveis, como a quadratura do círculo [grifo meu]
etc., há outras que, embora sejam possíveis, estendem-se, contudo, para além dos
limites que coloquei, não porque exigem outras regras ou mais espírito, mas porque é Boletim Cearense de Educação e História da Matemática - Volume 03, Número 08, 30 - 46(2016) 
preciso mais trabalho (...). Enfim, há as que pertencem à aritmética e não à geometria, como aquelas de Diofanto (DESCARTES, AT, 1995-1998 apud CRIPPA, 2010, p. 598).

Porém, encontrado entre alguns manuscritos de Descartes, entre os anos de 1625 e 1628, há uma solução, atribuída a Descartes, para o problema. Sendo que, segundo Crippa (2010, p. 600), “a primeira referência a essa demonstração é atribuída a Euler" que faz referência a este manuscrito em sua obra Annotationes in locum quendam Cartesii ad circuli quadraturam spectantem de 1763.

Contudo, a solução dada por Descartes não lhe pareceu ser de todo satisfatória por ir além do uso de seu próprio método exposto em A geometria. Referente ao problema da quadratura, Descartes esclarece que

[p]ara quadrar o círculo, nada encontro de mais apto do que, sendo dado um quadrado $b f$, juntar o retângulo $c g$, delimitado pelas linhas $a c$ e $c b$, igual à quarta parte do quadrado $b f$; e, em seguida, juntar o retângulo $d h$, formado pelos segmentos $d a, d c$, igual à quarta parte do precedente; $\mathrm{e}$, da mesma maneira, juntar o retângulo ei e outros infinitos até atingir o ponto $x$. Todos eles juntos comporão a terça parte do quadrado $b f$. E esta linha $a x$ será o diâmetro do círculo, cuja circunferência é igual ao perímetro desse quadrado $b f$. Por outro lado, $a c$ é o diâmetro do círculo inscrito no octógono isoperimétrico ao quadrado $b f$, ad é o diâmetro do círculo inscrito na figura de 16 lados e $a e$, o diâmetro inscrito na figura de 32 lados, isoperimétrico ao quadrado $b f$; e assim ao infinito (DESCARTES, AT, 10, p. 304-5, apud CRIPPA, 2010, p. 599).

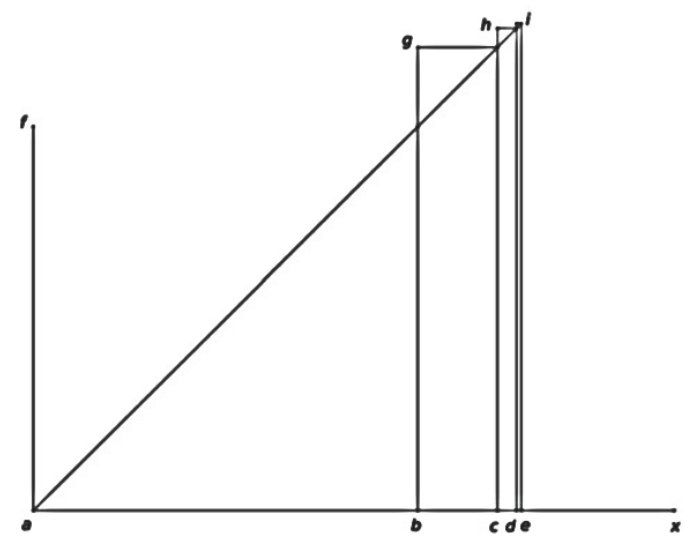

Figura 2. Quadratura do círculo (CRIPPA, 2010, p. 599)

Assim, Descartes propõe uma solução para uma reformulação do problema da quadratura do círculo, que, segundo Crippa (2010, p. 600), pode ser resumida a: "sendo dada a medida da circunferência, pede-se que se encontre seu diâmetro". A partir deste resultado e sabendo-se que "[t]odo círculo equivale [em área] ao triângulo retângulo no qual um dos lados adjacentes ao ângulo reto é igual ao raio e o outro é igual ao perímetro [circunferência]" (Arquimedes, 1960, p. 127; Heiberg, 1910-1915, 1, p. 259 apud CRIPPA, 2010, p. 600) que 
Descartes tinha conhecimento, pode-se concluir que o problema da quadratura do círculo está solucionado.

A solução dada por Descartes, mostra, conforme Crippa (2010) observa, que ele forneceu a soma da progressão geométrica $\sum \frac{1}{4^{n}}=\frac{1}{3}$. Porém, Descartes não fica satisfeito com sua solução e nem ao menos é divulgada, salvo em uma carta que foi direcionada para alguns de seus interlocutores.

Tais procedimentos e os procedimentos empregados em sua A Geometria foram fundamentais para a criação do Cálculo Diferencial e Integral que seria criado simultaneamente anos depois por Newton e Leibniz (BOYER, 1959; STRUIK, 1989).

\section{A Geometria}

A Geometria é uma das obras matemáticas mais importantes de René Descartes. Esta seção será dedicada à esta obra, mostrando como o seu autor introduziu algumas noções que hoje em dia é de fácil compreensão, mas que em sua época não eram conhecidas, tais como o produto entre dois segmentos de reta, raiz de um segmento, tratar geometria algebricamente. Também discutir um pouco sobre o problema de Pappus, que assim como o problema da quadratura do círculo, foi um legado deixado pelos antigos geômetras.

Descartes inicia sua obra A geometria alertando que não iria preocupar-se em se fazer entendido por todos os seus leitores, como havia feito até o momento em O Discurso do Método e em outros escritos seus. Esta obra exigiria que para ser completamente entendida, o leitor precisaria ter um mínimo de conhecimento em geometria, conhecimento que o escritor não exigiu para que compreendessem suas obras anteriores. Quanto a isso, em uma carta direcionada a Mersenne, ele explica: "Nos meus escritos anteriores eu tentei me fazer claro para todo mundo; mas eu tenho dúvidas se esse tratado será lido por alguém que não seja familiarizado com livros de Geometria, e então eu julguei supérfluo repetir demonstrações contidas neles" (DESCARTES, 2009, nota 8, p. 230).

Contudo, Descartes se via cético quanto ao interesse de pessoas que não tinham certa dedicação ao estudo da matemática nesta obra específica, utilizando isso como justificativa para não fazer algumas demonstrações que se é possível encontrar em outros livros de geometria, como, por exemplo, em Os elementos de Euclides (360 a.C. - 295 a.C.), por tal motivo, tal obra possui um teor menos demonstrativo e mais expositivo de resultados obtidos por Descartes, com isso, sua obra se tornou difícil até mesmo para alguns daqueles "que já conheçam o que 
está nos livros de Geometria” (DESCARTES, 2009 [1637], p. 221). Para início de sua teoria, ele deixa claro o seu objetivo,

Como toda a Aritmética consiste apenas em quatro ou cinco operações, a saber, adição, subtração, multiplicação, divisão e a extração das raízes, que pode ser considerada um tipo da divisão, assim também não há outra coisa a fazer em Geometria, com respeito às linhas que se desejam conhecer, senão a elas adicionar ou subtrair outras para prepará-las para serem conhecidas ou, ainda, tomando uma, que chamarei de unidade a fim de relacioná-la o melhor possível com os números [grifo meu], a qual pode em geral ser escolhida arbitrariamente, e conhecendo outras duas, encontro uma quarta que esteja para uma dessas duas como a outra está para a unidade, que é o mesmo que a multiplicação; ou ainda encontrar uma quarta que esteja para uma dessas duas como a unidade está para a outra, o que é o mesmo que a divisão [...]. E não temerei introduzir esses termos da Aritmética na Geometria para me fazer compreender melhor (DESCARTES, 2009 [1637], p. 224).

À guisa de exemplo, Descartes diz ser o segmento $\mathrm{AB}$ a unidade, para multiplicar $\mathrm{BD}$ por BC, basta apenas unir os pontos A e C e traçar uma paralela DE a AC chegando-se, comparando triângulos, a conclusão de que a multiplicação BD por BC é o segmento de reta BE.

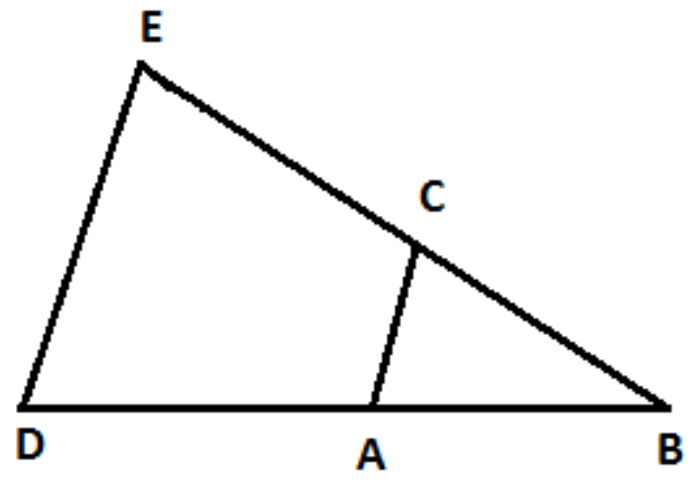

Figura 3: Produto entre BD e BC.

Atualmente, este método não possui grandes novidades, mas para a época, era grande inovação. De acordo com o critério da homogeneidade das grandezas, presente na época, o produto de dois segmentos de reta deveria ser necessariamente uma área, porém, vale observar que neste exemplo é possível que o produto entre dois segmentos continue dando um segmento e não uma área. Ou seja, pelo critério de homogeneidade das grandezas, o produto de BD por BC deveria ser equivalente a um retângulo, mas Descartes, desconsiderando tal critério, mostra que este produto ainda é um segmento, a saber, BE.

De modo semelhante, Descartes introduz outras operações aritméticas como divisão e radiciação: 
se se pretende dividir $\mathrm{BE}$ por $\mathrm{BD}$, tendo unido os pontos $\mathrm{E}$ e $\mathrm{D}$, traça-se AC paralela a DE; BC é o resultado desta divisão.

No caso em que se pretende extrair a raiz quadrada de $\mathrm{GH}$, adiciona-se ao longo da linha reta FG, que é igual à unidade, e dividindo $\mathrm{FH}$ em duas partes iguais pelo ponto $\mathrm{K}$, descrevo a partir de K o círculo FIH. Depois, traçando do ponto $\mathrm{G}$ uma reta com ângulos retos sobre FH, até I, GI é a raiz buscada (DESCARTES, 2009, p. 225).

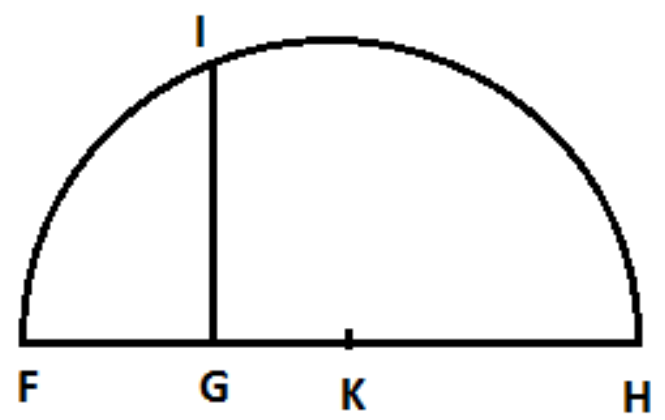

Figura 4. Raiz do segmento GH.

Para provar que o segmento BC é a divisão de BE por BD, ou que GI é a raiz quadrada de GH, Descartes utiliza relações geométricas conhecidas na época, e descritas por Euclides em seus Elementos.

Descartes também deixa claro que não é preciso desenhar os segmentos no papel para poder operar com estes segmentos, para isto, basta chamá-los por letras, como, por exemplo, o segmento $\mathrm{AB}$ pode ser identificado por $a$. Em seguida, expõe como proceder no caso de equações:

\begin{abstract}
Assim, querendo se resolver algum problema, deve-se previamente considerá-lo como já realizado e dar nome a todas as linhas que parecem necessárias para o construir, tanto às que são desconhecidas quanto às outras. Então, sem fazer qualquer distinção entre as linhas conhecidas e as desconhecidas, deve-se examinar a dificuldade segundo a ordem que mostre, de modo mais natural, de que modo elas dependem mutuamente umas das outras até que se tenha encontrado a maneira de expressar uma mesma quantidade de dois modos, o que se denomina equação, pois os termos de um desses dois modos deve[m] ser igua[is] àquele[s] do outro. E se deve encontrar tantas dessas equações quantas são supostas serem as linhas desconhecidas. Caso contrário, se não puderem ser encontradas, apesar de não se ter omitido nada daquilo que se deseja no problema, isso prova que ela não está inteiramente determinad[a] e, então, se pode escolher arbitrariamente as linhas conhecidas para todas as desconhecidas às quais não correspondem nenhuma equação [...]. Deste modo pode-se sempre reduzir todas as quantidades desconhecidas a uma única, quando o problema pode ser construído através de círculos e linhas retas, ou ainda por secções cônicas ou mesmo por alguma outra linha que não seja composta de mais do que um ou dois graus. (DESCARTES, 2009 [1637], p. 226-229).
\end{abstract}

Encerrando o assunto sobre operações aritméticas e equações, Descartes esclarece 
Todavia, não me detenho a explicar isso com mais detalhe, pois eu vos privaria do prazer de aprender por vós mesmos, e a utilidade de cultivar vosso espírito exercitando-o é, em minha opinião, o que há de mais importante que se pode obter desta ciência. Não me refiro, também, a nada tão difícil que aqueles que sejam um pouco versados na Geometria elementar e na Álgebra [grifo meu], e que se apliquem com cuidado a tudo o que está neste tratado, não possam encontrar (DESCARTES, 2009 [1637], p. 230).

Deve-se perceber que, segundo Descartes, é preciso que se tenha certo conhecimento em Geometria e Álgebra elementares para que o leitor possa tirar todo o proveito possível e compreender profundamente a sua obra. Deve-se ainda ressaltar que Descartes, nesta obra, não reconhecia as raízes negativas ${ }^{5}$. Embora os números negativos já fossem conhecidos e apareciam em determinados exemplos, os matemáticos ainda não os reconheciam como números propriamente ditos, portanto, não se trabalhava com equações como hoje em dia se trabalha, elas eram tratadas separadamente de maneira a evitar que o resultado fosse negativo.

Para tanto, à guisa de exemplo, sendo z o valor desconhecido da equação $z^{2}=a z+b^{2}$, para se chegar a sua solução, deve-se construir um triângulo retângulo NLM de tal maneira que $L M=b$ que é a raiz de $b^{2}$, ou seja, chama-se o segmento LM de b. De mesmo modo, faz $N L=$ $\frac{a}{2}$. Prolongando o segmento $\mathrm{MN}$ até $\mathrm{O}$ de forma que $N O=N L=\frac{a}{2}$ tem-se que o círculo de raio $\frac{a}{2}$ e de centro $\mathrm{N}$ passa por $\mathrm{O}, \mathrm{L}$ e um ponto $\mathrm{P}$ entre $\mathrm{MN}$. Portanto, o segmento $M O=z$ é a linha procurada, pois os triângulos OLM e LPM são semelhantes pelo caso ângulo-lado-ângulo e por relações de semelhanças entre triângulos, chega-se ao resultado.

Ela é expressa, segundo Descartes, por

$$
z=\frac{a}{2}+\sqrt{\frac{a^{2}}{4}+b^{2}}
$$

Atualmente, como consideramos os números negativos como números propriamente dito, temos que a solução para essa equação é

$$
z=\frac{a}{2} \pm \sqrt{\frac{a^{2}}{4}+b^{2}}
$$

${ }_{5}^{5}$ Atualmente, se tratando de medições, não se considera as raízes negativas por não haver comprimentos negativos. Boletim Cearense de Educação e História da Matemática - Volume 03, Número 08, 30 - 46(2016) 


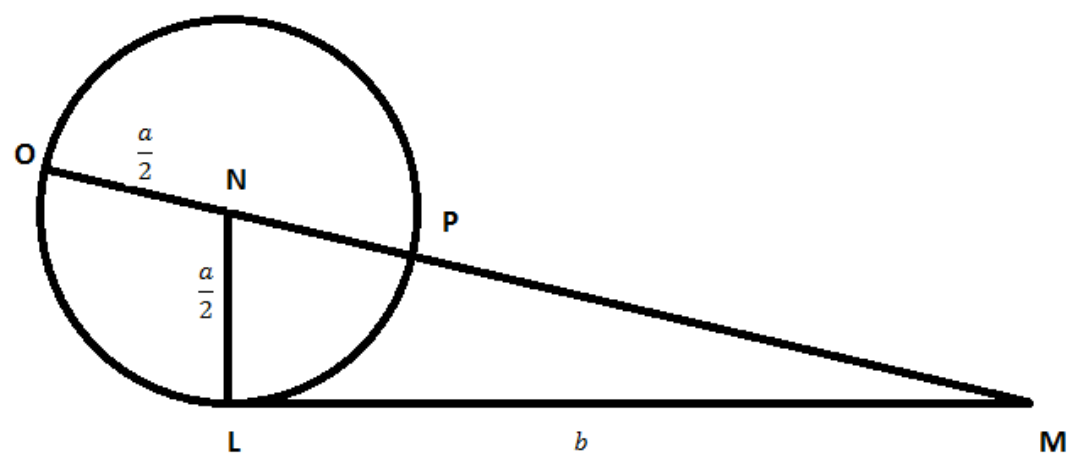

Figura 5: Raiz da equação $z^{2}=a z+b^{2}$.

Em seguida, o pensador expõe o problema de Pappus (c. 290 - c. 350 a.C.) que, segundo ele, nem Euclides, nem Apolônio (292 a.C. - 194 a.C.), nem qualquer outro matemático havia conseguido solucionar inteiramente (DESCARTES, 2009 [1637], p. 234).

\begin{abstract}
Dado[s] três ou quatro ou mais números de linhas retas pela posição, deve-se, primeiramente, encontrar um ponto a partir do qual se possam traçar outras linhas retas, fazendo cada uma um ângulo dado com uma das anteriores, de modo que o retângulo formado por duas dessas assim traçadas do mesmo ponto tenha a proporção dada com o quadrado da terceira, se não há mais do que três; ou, se houver quatro, com o retângulo das outras duas ou, ainda, havendo cinco, que o paralelepípedo formado por três tenha uma dada proporção com o paralelepípedo das duas que restam e de outra linha dada. Ou, se há seis, que o paralelepípedo composto por três tenha uma proporção dada com um paralelepípedo de três outros. Ou, havendo sete, aquilo que se obtém multiplicando quatro, tenha uma dada razão com o produto das três restantes por outra linha dada. Ou, se há oito, que o produto da multiplicação de quatro tenha a proporção dada com o produto das outras quatro. E, assim, se pode estender este problema a qualquer quantidade de linhas (DESCARTES, 2009 [1637], p. 238).
\end{abstract}

Segundo o próprio Pappus, a solução para este problema seria uma infinidade de pontos resultante em uma cônica. Tais figuras geométricas já eram conhecidas desde a antiguidade (BOYER, 1996, p. 99 apud nota 17 in DESCARTES, 2009 [1637], p. 239).

Contudo, nas investigações de Descartes, feitas em apenas cinco ou seis semanas, ele concluiu que o problema era proposto para 3, 4 ou 5 linhas, cujo o resultado poderia ser encontrado pela geometria elementar (fazendo uso somente da régua e compasso); para cinco linhas paralelas e 6, 7,8 ou 9 linhas, a solução é dada pela geometria dos sólidos, através das cônicas; para nove linhas paralelas e 10,11, 12 e 13 linhas, tem-se a resposta dada por linha curva de um grau a mais que as cônicas; para 13 linhas paralelas e 14, 15, 16 e 17 linhas, é preciso uma linha curva de um grau maior; e assim sucessivamente ao infinito. Muitas vezes, 
para o caso de 3 ou 4 linhas, a solução se encontra em uma circunferência ou em uma linha reta; (DESCARTES, 2009 [1637], p. 239-240).

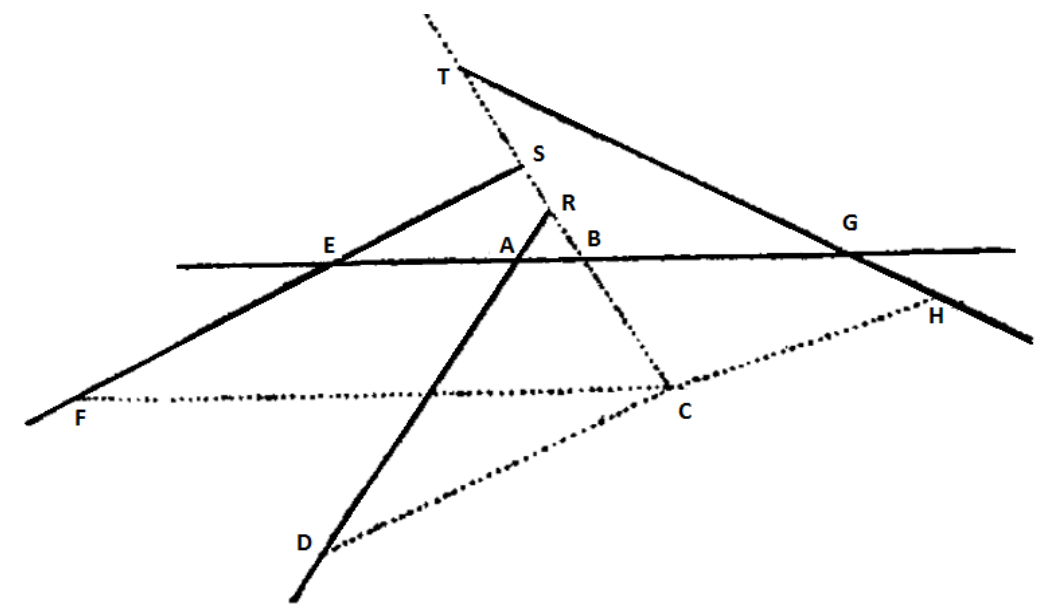

Figura 6: Problema de Pappus, (DESCARTES, 2009 [1637]).

Para exemplificar, Descartes propõe a solução para o problema na figura 6, em poucas palavras, pois estava cansado de tanto escrever (DESCARTES, 2009 [1637], p. 241-244).

Sejam AB, AD, EF, GH, etc. linhas dadas em posição. Considerando que o produto de uma parte destas linhas seja igual ao produto das outras e que as linhas tenham proporções dadas, por exemplo, $C F * C D=c * C H * C B$, onde c é uma constante, tem-se o objetivo de encontrar o ponto $\mathrm{C}$ tal que linhas tais como $\mathrm{CB}, \mathrm{CD}, \mathrm{CE}$ e $\mathrm{CH}$ tenham os ângulos $\mathrm{CBA}, \mathrm{CDA}$, CFE, CHG, etc. dados.

Para tal, deve-se considerar o problema como resolvido e considera-se duas linhas, uma dada e outra que queira se encontrar, por exemplo, $\mathrm{AB}$ e $\mathrm{CB}$, como linhas principais. Nomeiase esses segmentos como $A B=x$ e $B C=y, \log$, como BC é desconhecido, Descartes trabalha com ele como se já o conhecesse, um determinado valor y. Em seguida, prolonga-se todas as linhas, se necessário, de forma que elas se interceptem. Como indicado na Figura 6, a linha AB é cortada nos pontos $\mathrm{A}, \mathrm{E}$ e $\mathrm{G}$ e a linha $\mathrm{BC}$ nos pontos $\mathrm{B}, \mathrm{R}, \mathrm{S}$ e T.

Pelo fato dos ângulos do triângulo ARB serem conhecidos, a proporção de seus lados também o é, o qual Descartes faz $\frac{A B}{B B}=\frac{b}{z}, \operatorname{logo} R B=\frac{b x}{z}$, além disso $C R=y+\frac{b x}{z}$, pois B está entre C e P. Teríamos $C R=y-\frac{b x}{z}$, se R estivesse entre C e B, ou $C R=-y+\frac{b x}{z}$, se C estivesse entre B e R.

Analogamente, sendo $\frac{C D}{C R}=\frac{c}{z}$, temos, como $C R=y+\frac{b x}{z}, C D=\frac{c y}{z}+\frac{b c x}{z z}$. 
A partir das linhas dadas, tem-se que a distância entre A e E também é dada, ou seja, $\overline{A E}=k, \operatorname{logo}, E B=k+x$; mas teríamos $E B=k-x$, se B estivesse entre $\mathrm{E}$ e $\mathrm{A}$ e $E B=-k+$ $x$, se E ficasse entre A e B.

Sendo $\frac{B S}{B E}=\frac{d}{z}, B S=\frac{d k+d x}{z}$ e $C S=\frac{z y+d k+d x}{z}$, pois B está entre C e S. Todavia, teríamos $C S=\frac{z y-d k-d x}{z}$, se $S$ estivesse entre B e C, e $C S=\frac{-z y+d k+d x}{z}$, se C estivesse entre B e S. De modo análogo, sendo $\frac{C F}{C S}=\frac{e}{z} \Rightarrow C F=\frac{e z y+d e k+d e x}{z z}$. Como $A C=l$ é dado, $B G=l-x$, sendo $\frac{B T}{B G}=\frac{f}{z} \Rightarrow B T=\frac{f l-f x}{z}$ e $C T=\frac{z y+f f-f x}{z}$, sendo $\frac{C H}{T C}=\frac{g}{z} \Rightarrow C H=\frac{g z y+f g l-f g x}{z z}$.

Deve-se observar, que, tomando a relação de proporcionalidade entre as linhas dadas e, com $y$ é conhecido, terá $y$ como equação de segundo grau em relação a $x$ que pode ser encontrado utilizando o método já descrito proposto por Descartes. Então ele conclui,

[n]otareis, assim, que qualquer que seja o número de linhas dadas por posição, todas as linhas traçadas a partir do ponto $\mathrm{C}$ tem ângulos dados conforme o enunciado e um é composto pela quantidade desconhecida $y$ multiplicada, ou dividida, por alguma outra conhecida; o outro pela quantidade desconhecida $x$ também multiplicada ou dividida por alguma outra conhecida, e o terceiro por uma quantidade totalmente conhecida. Excetua-se somente o caso delas serem paralelas quer à linha $\mathrm{AB}$, caso em que o termo composto da quantidade $x$ será nulo, quer à linha $\mathrm{CB}$, caso em que o termo composto da quantidade $y$ será nulo, o que fica suficientemente claro para que não me detenha a explicar mais. Quanto aos sinais $+\mathrm{e}-$ que se unem a estes termos, eles podem ser mudados de todas as maneiras imagináveis.

Podeis notar também que, multiplicando várias dessas linhas uma pela outra, as quantidades $x$ e $y$ que se encontram no produto não podem ter cada uma senão tantas dimensões quanto são as linhas, a explicação delas será dada assim que sejam multiplicadas. Elas não terão jamais mais do que duas dimensões, o que não será produzido senão pela multiplicação de duas linhas, nem mais do que três, o que não será produzido senão pela multiplicação de três, e, assim, ao infinito. (DESCARTES, 2009 [1637], p. 244-245).

Por fim, esclarece algumas especificidades para casos em que há mais linhas no problema de Pappus. E, portanto, Descartes esclarece que essas construções geométricas devem ser expandidas, não só para construções a partir de régua e compasso, mas também com curva de maior grau, ou seja, "pode-se sempre fazer de modo que a equação não chegue mais do que até o quadrado do cubo, de modo que possa sempre se resolver por meio de uma linha que não é senão apenas um grau mais composta do que as secções cônicas" (DESCARTES, 2009 [1637], p. 246-247). 
Deve-se, contudo, observar que o sistema de coordenadas que Descartes usou para resolver o exemplo que ele apresenta em sua obra, não foi um sistema ortogonal, foi, entretanto, um sistema que melhor se adequasse ao problema, como de fato era usual em sua época (ROQUE, 2015). Uma observação importante feita por Roque (2015) é que esse método proposto por Descartes só é possível ao se tratar de problemas indeterminados, ou seja, problemas que se tratam do que chamamos hoje de duas variáveis. A professora e escritora Tatiana Roque também ressalta que matemáticos como Viète, embora tivessem as ferramentas necessárias em mãos - álgebra e geometria - não estavam interessados em tratar problemas indeterminados. Para eles, o que interessava eram os problemas determinados, ou seja, de uma única variável, como é dito hoje.

\section{Considerações Finais}

Descartes nasce inserido em um contexto histórico importante para a ciência em geral, a Revolução Científica, e como cientista, dá sua contribuição, tanto para a filosofia, quanto para a matemática e demais ciências que se formaram posteriormente dele. Para a filosofia de um modo especial, hoje essa contribuição lhe é reconhecida ao ser chamado de pai da Filosofia Moderna.

Matematicamente, suas contribuições são de grande importância. Hoje, o plano ortogonal e o sistema de coordenadas quadradas recebem, muitas vezes, o seu nome. Sua obra contribuiu imensamente para a criação do Cálculo Diferencial e Integral por Newton e Leibniz anos depois de suas publicações. Muitos outros matemáticos também foram influenciados por seu trabalho.

Para Descartes, seu método era de suma importância, tanto que, mesmo tendo encontrado uma solução para um dos três grandes problemas da Antiguidade, a quadratura do círculo $^{6}$, ele não deu grandes importâncias para seu resultado, por não ter aplicado o seu próprio método.

A geometria possui um grande valor matemático para a história da matemática. Nesta obra, Descartes não só faz uma correspondência entre retas (segmentos de restas) e números, como também propõe a solução para um problema antigo, que, segundo seu criador, não poderia ser resolvido pelos antigos geômetras: Problema de Pappus. Todavia, Descartes não está interessado em determinar o lugar geométricos formado pelos pontos $\mathrm{C}$ no problema (ROQUE,

${ }^{6}$ Os demais problemas são: trissecção do ângulo e duplicação do cubo.

Boletim Cearense de Educação e História da Matemática - Volume 03, Número 08, 30 - 46(2016) 
2015), mas em aplicar o seu método para encontrar a solução. Em suma, ele propõe um método que poderia ser generalizado e através dele chegar à solução em qualquer nível do problema, não só para construções geométricas fazendo uso de régua e compasso, mas também utilizando equações de grau mais elevado.

Com este método, Descartes lança as bases da hoje chamada Geometria Analítica. Embora, Descartes tenha adaptado o sistema de coordenadas de forma que se adaptasse melhor ao problema não fazendo uso de um sistema de coordenadas ortogonais, hoje este sistema ortogonal recebe o seu nome: sistema de coordenadas cartesiano, revelando a influência que sua obra teve na matemática posterior a ele.

\section{Referências}

ABBGNANO, N. Dicionário de Filosofia. São Paulo: Martins Fontes, 2007.

ANDRADE, E. Introdução. In: DESCARTES, R. O mundo ou tratado da luz. São Paulo: Hedra, 2008. p. 9-18.

ARQUIMEDES. La mesure du cercle. In: CRIPPA, D. A solução cartesiana da quadratura do círculo. scientiæ zudia, São Paulo, v. 8, n. 4, p. 597-621, 2010 [1960].

BOYER, C. B. The History of the Calculus and its Conceptual Development: the Concepts of the Calculus. New York: Dover, 1959.

CRIPPA, D. A solução cartesiana da quadratura do círculo. scientiæ zudia, São Paulo, v. 8, n. 4, p. 597-621, 2010.

DESCARTES, R. A Geometria. Caderno de História e Filosofia da Ciência: Campinas, v. 19, n. 2, p. 223-251, 2009.

Discurso do método. Brasília, Universidade de Brasília, 1985.

Princípios da Filosofia. São Paulo: Hemus, 1968.

Regras para a direção do espírito. Lisboa: Edições 70, 1989.

HEIBERG, J. L. (Ed.). Archimedis opera omnia cum commentariis Eutocii. In: CRIPPA, D. A solução cartesiana da quadratura do círculo. scientiæ zudia, São Paulo, v. 8, n. 4, p. 597621,2010 [1910]. 
NIEBEL, W. F. HORN, A. SCHNÄDELBACH, H. Descartes im Diskurs der Neuzeit. Frankfurt am Main: Suhrkamp, 2000.

REALE, G. ANTISERI, D. História da Filosofia: do humanismo a Descartes. São Paulo: Paulus, 2004.

ROQUE, T. História da Matemática: uma visão crítica, desfazendo mitos e lendas. Rio de Janeiro: Zahar, 2012.

História da Matemática para Professores 11 - René Descartes. 2015. Disponível em: <https://youtu.be/6yFGXZJy5CA>. Acessado em 26/10/2015.

ROSSI, P. O nascimento da ciência moderna na Europa. Bauru: EDUSC, 2001.

SOUZA, J. L. C. A Matemática Metafísica de René Descartes. Traços. Belém, v. 6, n. 12, p. 83-95, 2003.

STRUIK, D. J. História concisa das matemáticas. Lisboa: Gradiva, 1989.

VAZ, D. A. F. Reseña de "A Geometria” de DESCARTES, René. Boletim de Educação Matemática. Rio Claro, v. 18, n. 23, 2005.

A Matemática e a Filosofia de René Descartes. Disponível em

<http://www.educadores.diaadia.pr.gov.br/arquivos/File/2010/artigos_teses/FILOSOFIA/Arti gos/Duelci.pdf $>$, acessado em 22/10/2015. 